\title{
招待講演 2
}

\section{Pierre Amarenco}

Xavier Bichat Medical School, Denis Diderot University, Paris, France

Professor Pierre Amarenco is Professor of Neurology at the Xavier Bichat Medical School, Denis Diderot University in Paris, France, a position he has held since 2001. He is also Chairman of the Department of Neurology and Stroke Center at Bichat Hospital in Paris, France.

Professor Amarenco received both his medical degree and MD from the University of Paris Medical School. After receiving his specialist certificate in Neurology, he went on to obtain Masters in Neuroscience at Pierre and Marie Curie University in Paris, France. Professor Amarenco was the recipient of awards such as Jean-Paul Binet Award for clinical research in cardiovascular disease of the Medical Research Foundation and Award of the Second European Stroke Conference.

Professor Amarenco has served as Principal Investigator for numerous stroke-related trials including the French study of Aortic Plaques in Stroke, The Aortic Arch Related Cerebral Hazard (ARCH) trial, the Lacunar Brain Infarction Cerebral Hypereactivity and Atorvastatin trial, the Multiple Atherosclerotic Site in Stroke autopsy Study, and the GENIC (etude du profil GENetique de l' Infarctus Cerebral) study. He serves as a member of the steering committee of the Stroke Prevention by Aggressive Reduction of Cholesterol Levels (SPARCL) study. He is the Funding Editor-in-Chief for La Lettre du Neurologue and served on Editorial Board of many other internationally renown journals such as Stroke. Professor Amarenco has presented nearly 90 lectures in meetings worldwide and has published over 150 articles in peer-reviewed journals including 3 as first author in the New England Journal of Medicine, and 35 book chapters. 


\section{Lipid and stroke}

The occurrence of stroke increases with age, particularly affecting the older elderly, a population also at higher risk for coronary heart disease (CHD), Epidemiologic and observational studies have not shown a clear association between cholesterol levels and all causes of stroke. Nonetheless, large, long-term statin trials in patients with established or at high risk of coronary heart disease have shown that statins decrease stroke incidence.

We performed a systematic review and meta-analysis of all statin trials which have now included over 90,000 patients, to determined the effect of statins and LDL-C reduction on stroke prevention. 1 The relative risk reduction for stroke was $21 \%$ (OR 0.79 [0.73-0.85]) with no heterogeneity between trials. Fatal strokes were reduced, but not significantly, by $9 \%$ (OR $0.91[0.76-1.10]$ ). There was no increase in haemorrhagic strokes (OR 0.90 [0.65-1.22]). The extent of statin's effect was closely associated with LDL-C reduction. LDL reduction explained 34 to $80 \%$ of the observed benefit, leaving also room for other, pleotropic, effects. Each 10\%reduction in LDL-C was estimated to reduce the risk of all strokes by $13.2 \%(95$ $\% \mathrm{CI}, 4.8-20.6)$ and carotid intima-media thickness (IMT) by $0.73 \%$ per year $(95 \% \mathrm{CI}=0.27-1.19)$. By comparison, the number of strokes prevented per 1000 patients treated for 5 years in patients with coronary heart disease is 6.4 for statins versus 17.3 for antiplatelet agents. Our meta-analysis shows that statins may reduce the incidence of all strokes without any increase in hemorrhagic strokes, and this effect is mainly driven by the extent of between-group LDL-C reduction.

Statins have not yet been shown to reduce stroke risk in the typical general population without known coronary heart disease, nor have they been shown to prevent recurrent stroke in patients with prior stroke. Potential reasons for the effects of statins on stroke and the non-cholesterol-lowering mechanisms that may be involved will be discussed. Additional studies in patients representative of the typical stroke population are needed.

Statins have a good overall safety profile with no increased incidence of hemorrhagic stroke and cancer. They have positive effects in primary prevention of cardiovascular disease in high risk young as well as elderly populations. Statins reduced stroke incidence in high risk populations-mainly CHD, diabetics in Heart Protection Study (HPS) and Collaborative AtoRvastatin Diabetes Study (CARDS) trial and hypertensives in Anglo-Scandinavian Cardiac Outcomes Trial (ASCOT) trial-even with a normal baseline blood cholesterol level, which argues for a global cardiovascular risk-based treatment strategy. 2-4 In patients with prior strokes, statins reduce the incidence of coronary events as shown by the HPS trial, but it is not yet proven that statins actually reduce the incidence of recurrent strokes in secondary prevention. 3

Based on the evidence, there are no longer discussions that for all stroke patients with a past history of myocardial infarction clinicians should consider adding a statin, even when serum cholesterol level is in the 'normal' range. In patients with ischemic stroke with no past history of coronary event, who constitutes $80 \%$ of the stroke population, no clear recommendation can be made. The Stroke Prevention by $\mathrm{Ag}$ gressive Reduction in Cholesterol Levels (SPARCL) study is a unique large randomized, placebo- 
controlled trials which is on-going and will definitely answer this question with aggressive cholesterol lowering with atorvastatin $80 \mathrm{mg} /$ day in patients with stroke and no past-history of cerebrovascular disease. 5 Results will be avalaible in early 2006.

\section{References}

1) Amarenco $P$, Labreuche J, Lavallee $P$, et al. Statins in stroke prevention and carotid atherosclerosis : systematic review and up-to-date meta-analysis. Stroke 2004 ; 35 : 2902-2909.

2) Colhoun HM, Betteridge DJ, Durrington PN, et al. Primary prevention of cardiovascular disease with atorvastatin in type 2 diabetes in the Collaborative Atorvastatin Diabetes Study (CARDS) : multicentre randomised placebo-controlled trial. Lancet $2004 ; 364: 685-696$.

3) Heart Protection Study Collaborative Group. MRC/BHF Heart Protection Study of cholesterollowering with simvastatin in 5963 people with diabetes : a randomised placebo-controlled trial. Lancet $2003: 361: 2005-2016$.

4) Sever PS, Dahlof B, Poulter NR, et al. Prevention of coronary and stroke events with atorvastatin in hypertensive patients who have average or lower-than-average cholesterol concentrations, in the Anglo-Scandinavian Cardiac Outcomes Trial-Lipid Lowering Arm (ASCOT-LLA) : a multicentre randomised controlled trial. Lancet $2003 ; 361: 1149-1158$.

5) Amarenco P, Bogousslavsky J, Callahan AS, et al. Design and baseline characteristics of the stroke prevention by aggressive reduction in cholesterol levels (SPARCL) study. Cerebrovasc Dis 2003; 16 : $389-395$. 